\title{
Generation of Hydrocarbon Fuels from Mixed Polymer Wastes Using Decomposer Chamber
}

\author{
Giday Gebregziabher ${ }^{1,}$, , Solomon Mulaw ${ }^{1}$, Jemal Ebrahim $^{2}$, Abebe Tedla ${ }^{1}$, Haftu Gebretsadik ${ }^{1}$ \\ ${ }^{1}$ Department of Chemistry, College of Natural and Computational Science, Debre Berhan University, Debrebirhan, Ethiopia \\ ${ }^{2}$ Department of Mechanical Engineering, College of Engineering, Debre Berhan University, Debrebirhan, Ethiopia
}

Email address:

getgiday@gmail.com (G. Gebregziabher)

${ }^{*}$ Corresponding author

\section{To cite this article:}

Giday Gebregziabher, Solomon Mulaw, Jemal Ebrahim, Abebe Tedla, Haftu Gebretsadik. Generation of Hydrocarbon Fuels from Mixed Polymer Wastes Using Decomposer Chamber. Journal of Energy and Natural Resources. Vol. 7, No. 1, 2018, pp. 18-23.

doi: $10.11648 /$ j.jenr.20180701.13

Received: February 9, 2018; Accepted: March 13, 2018; Published: March 26, 2018

\begin{abstract}
Disposal of Waste plastics is one of the causes of major environmental problem in the world since they are not biodegradable. It is common to observe thrown plastic waste along with other trash material in the field especially in developing countries. It is indispensable to reduce the environmental concern by converting the plastic waste into hydrocarbon fuels by thermal degradation. In this study we report the conversion of mixed waste plastics (polymers) into hydrocarbon fuels such a slighter gas and liquid fuels using solid decomposer chamber as reactor. Different types of plastics including Low Density Polyethylene (LDPE), polypropylene (PP) and Polystyrene (PS), which have different melting point temperature ranges, were collected and used as raw materials. Reactor was designed and manufactured to thermally degrade these mixed plastic waste materials through Electric heating. The collected waste plastics were placed in the reactor and heated with different temperature ranges from 40 to $300^{\circ} \mathrm{C}$, thereby producing hydrocarbon fuels such as lighter gas $\left(\mathrm{C}_{1}-\mathrm{C}_{4}\right)$, naphtha $\left(\mathrm{C}_{7^{-}}\right.$ $\left.\mathrm{C}_{10}\right)$ and kerosene $\left(\mathrm{C}_{12}-\mathrm{C}_{15}\right)$ and were collected based on their temperature ranges. Chemical and physical properties of the products were analyzed qualitatively and the liquid products (naphtha $\left(\mathrm{C}_{7}-\mathrm{C}_{10}\right) \&$ kerosene $\left(\mathrm{C}_{12}-\mathrm{C}_{15}\right)$ ) formed were analyzed using FT-IR spectrometer spectrum to identify the existing functional groups. Most of the aliphatic compounds including Alkane, alkene, alkyl group and hydroxyls are present in the products.
\end{abstract}

Keywords: Hydrocarbon Fuel, Plastic Waste, Reactor, Thermal Degradation

\section{Introduction}

Polymer based plastics are commonly used in everyday activities of world society and thrown to the environment. The continuous increase in polymer plastic consumption and production leads to accumulation of large amounts of plastic wastes that pose serious environmental problems. The increase in application leads to a higher per capita consumption of virgin plastics and this pollution has created a major dilemma in the environmental conservation sector [1, 2]. Approximately, 230 million ton of waste plastics are generated worldwide each year. Unlike other waste materials, such as paper and food waste, waste plastics do not biodegrade, as they occupy landfill for a long period of time $[3,4]$.
Plastics are made up of long chain of molecules through polymerization called polymers. Plastic resins are made from derivatives of petroleum and natural gas. The monomers of plastic are either natural or synthetic organic compounds. There are three main types of polymers: thermoplastics, elastomers and thermosetting polymers $[1,5,6]$.

Most of the household plastic waste generated in Ethiopia is of thermoplastic type which includes mainly High-density polyethylene (HDPE), low density polyethylene (LDPE), polypropylene (PP), polyvinyl chloride (PVC), polystyrene (PS), and polyethylene terephtalate (PET) are the most extensively used plastics. The polyethylene plastics (HDPE and LDPE) are the major components of the total plastic content of municipal solid waste used for making carry bags, plastic bottles and milk and food containers etc [3, 5, 7].

There are several methods for disposal of municipal and 
industrial plastic waste, i.e. landfill, incineration and true material recycling. Effective utilization of polymer or plastic waste is vital for the implementation of well-known reduction, reuse and recycling [8, 9, 10]. Mechanical, chemical and energy recycling methods aims to recovering of polymer wastes to various valuable products (figure 1). Thus producing recyclates that can be converted into new plastics products, often substituting virgin plastics. But major drawbacks of this process are requirement of clean source of post-consumer plastics, the need for efficient separation technology to obtain generically pure resin types and labourintensive process $[7,11,12]$.

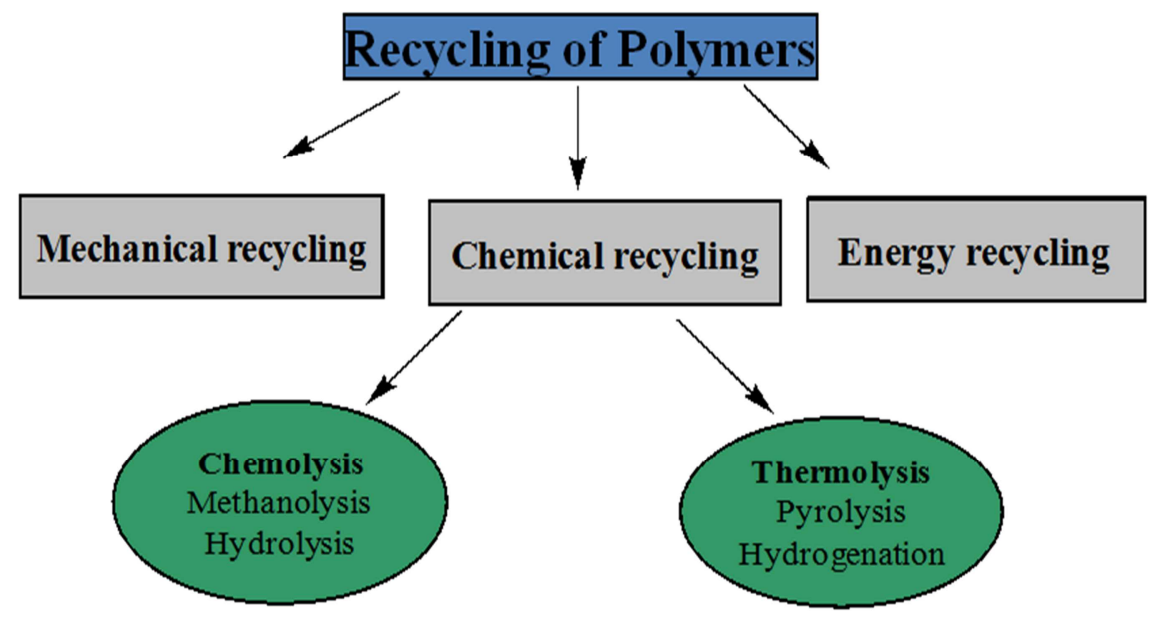

Figure 1. Methods of recycling polymers and related materials [13, 14].

In incineration facilities also, when the waste plastics are burned, harmful gases such as carbon dioxide, sulphur and nitrous oxide are released into the air. These significant expenditures and the environmental hazards caused by waste plastics have led to finding alternates of recycling and creating ways to utilize these waste plastics into valuable resources $[11,15,16]$. Conversion of plastics wastes into liquid fuel describes a range of plastic recovery techniques to make plastics, which break down polymers into their constituent monomers, which in turn can be used again in refineries, or petrochemical and chemical production $[4,17]$. Several methods for chemical recycling are presently in use, such as direct chemical treatment involving gasification, smelting by blast furnace or coke oven, and degradation by liquefaction, gasification and condensation polymers. Catalytic cracking and reforming facilitate the selective degradation of waste plastics [9, 18, 19].

Thermal degradation of mixed plastics is currently receiving renewed interest as route for disposal if the large quantities of plastic wastes collected by different collecting systems. The advantage of thermal degradation of macromolecules in the absence of air (pyrolysis) compared to combustion is a reduction in the volume of product gases leads to considerable savings in the gas conditioning equipment. Furthermore, it is possible to obtain valuable hydrocarbon fuels $[20,21]$. In this study we present a technology utilizing thermal degradation for converting the vast amount of waste plastic to useful hydrocarbon fuels such as hydrocarbon gases $\left(\mathrm{C}_{1}-\mathrm{C}_{4}\right)$, naphtha $\left(\mathrm{C}_{8}-\mathrm{C}_{11}\right)$, and kerosene $\left(\mathrm{C}_{12}-\mathrm{C}_{15}\right)$ because in this method the emission of hazardous gases to the environment insignificant. The efficiency of this technology is robust and the applications are feasible at a low cost.

\section{Method and Materials}

\subsection{Sample Collection and Preparation}

Waste plastic samples were collected from Debre Birhan town. Collected waste plastics were low density polyethylene (LDPE), polypropylene (PP) and Polystyrene (PS). These waste plastic were separated from foreign material and washed with water. Washed out waste plastic was put into grinder machine and grounded to size $8-10 \mathrm{~mm}$ for reactor setup.

\subsection{Solid Decomposer Chamber and Process Description}

The solid decomposer chamber (or reactor) is distillation type and made from $3 \mathrm{~mm}$ stainless steel and deep galvanized sheet with height of $1000 \mathrm{~mm}$, internal diameter $500 \mathrm{~mm}$. The solid decomposer chamber has gas pressure monitor, relieve valve, insulator, condenser (has water inlet and outlet), thermocouple, liquid fuel reservoir and lighter gases fuel reservoir. The external part of the reactor is covered by insulator to conserve heat. The reactor adjusted at angle of $70^{\circ}$ with condenser unit set for condensation. Condenser is made of $1500 \mathrm{~mm}$ long with galvanized round pipe one end is attached to the reactor and another end hook up with collection reservoir tanks. The reservoir tank has two ports, one part is set up with lighter gas fuel $\left(\mathrm{C}_{1}-\mathrm{C}_{4}\right)$ and the other bottom part is setup with liquid fuel hydrocarbon components.

The reactor is placed in the electrical stove for external heating with the raw material inside. $2 \mathrm{~kg}$ of raw materials (LDPE, PP and PS) were put into reactor chamber (seen figure 2). Fully closed the system experiment was performed. During the process no vacuum was created and no extra 
catalyst or any kind of chemical was added in this experiment. Reactor sample capacity is $5-7 \mathrm{~kg}$ but for our experiment we used only $2 \mathrm{~kg}$ waste plastic mixture. After setting up everything the reactor chamber was heated to a temperature of about $300^{\circ} \mathrm{C}$ and more. Reactor's temperatures were controlled using thermocouple which is assembling at the top of reactor.

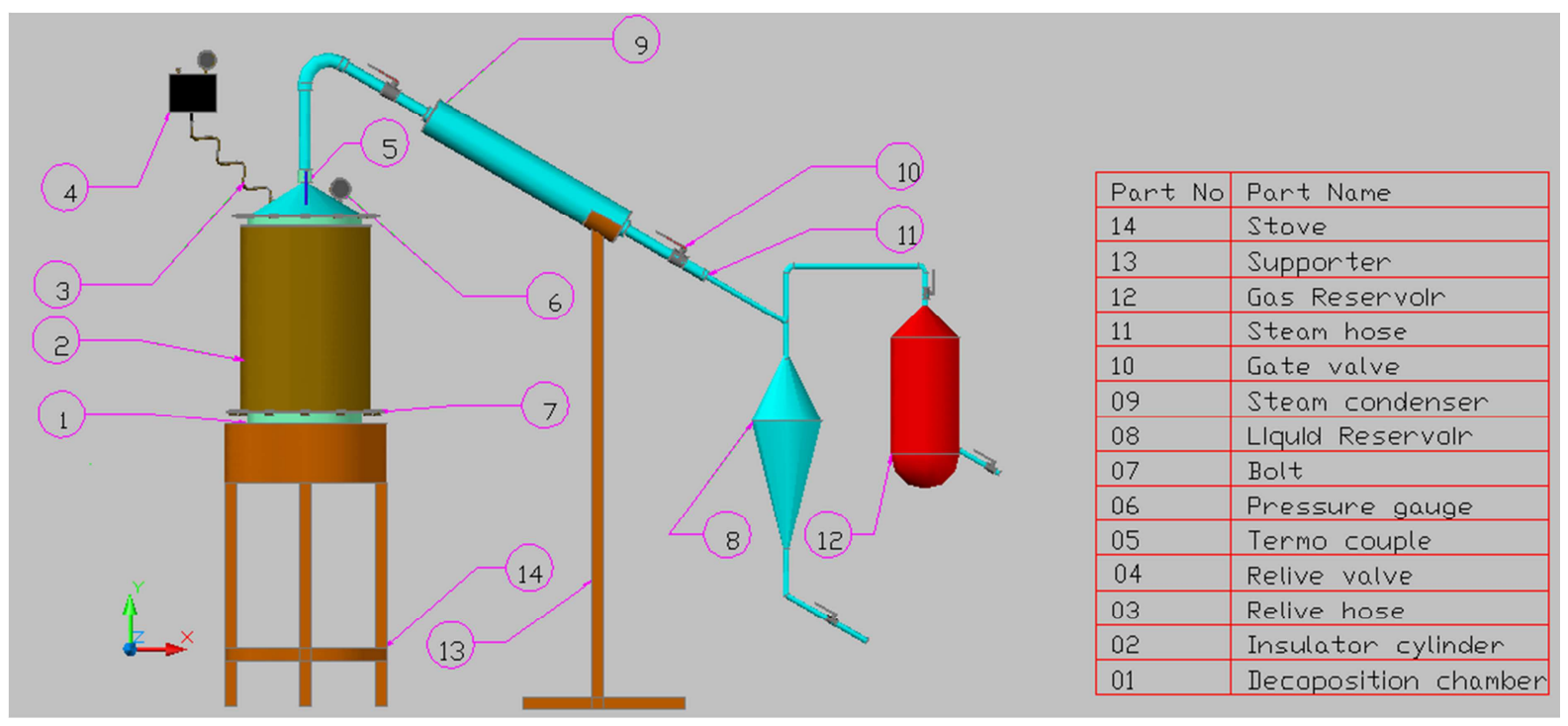

Figure 2. Solid decomposer chamber of polymer (plastic) wastes to fuel production process.

The experiment was started at temperature $40^{\circ} \mathrm{C}$ with fixed temperature ranges and temperature was increased every 10 minute by $8-10^{\circ} \mathrm{C}$ initially. The temperature range was adjusted from $40-60^{\circ} \mathrm{C}$ for hydrocarbon fuel gases $\left(\mathrm{C}_{1}-\mathrm{C}_{4}\right)$, $70-120^{\circ} \mathrm{C}$ for naphtha $\left(\mathrm{C}_{8}-\mathrm{C}_{11}\right)$ and $175-300{ }^{\circ} \mathrm{C}$ for kerosene $\left(\mathrm{C}_{12}-\mathrm{C}_{15}\right.$. The pressure of steam formed inside the reactor is controlled using pressure gauge and its safety by electrical pressure safety valve if the pressure was more. Melted waste plastic turn into gas vapour form when heat was increased gradually producing liquid form which at the end came out through the condenser unit into two reservoir parts.

\section{Results and Discussions}

Decomposer chamber machine was used as reactor in this study for thermal decomposition of the waste polymer plastics collected from different areas of Debre Berhan town, Ethiopia. No catalyst was used during thermal decomposition. During heating the mixture waste polymer plastics inside of the reactor have broken down from long chain hydrocarbon to different short chain hydrocarbon or monomers, which result in generation of liquid and gas hydrocarbon fuels. Based on their boiling point temperature ranges, the thermally cracked materials have been partitioned and moved out of the reactor at different temperature ranges. The reactor were connected to condenser that condensed the vapour of thermally cracked hydrocarbons into liquid while passing through it, and finally collected and characterized. Liquid fuels $(1.34 \mathrm{~L})$ were obtained from $2 \mathrm{~kg}$ raw materials. Further purification of the liquid fuels was carried out using fractional distillation to separate into naphtha and kerosene. During the process lighter gas $\left(\mathrm{C}_{1}-\mathrm{C}_{4}\right)$ fuel was produced were a mixtures of saturated hydrocarbons of methane $\left(\mathrm{CH}_{4}\right)$, ethane $\left(\mathrm{C}_{2} \mathrm{H}_{6}\right)$, propane $\left(\mathrm{C}_{3} \mathrm{H}_{6}\right)$, butane $\left(\mathrm{C}_{4} \mathrm{H}_{10}\right)$ and other lighter hydrocarbons.

The lighter gases was generated in the temperature range from $40^{\circ} \mathrm{C}$ to $60^{\circ} \mathrm{C}$. The resulting gas is colourless, vapour, light odour, combustible with air, easily flammable and has similar properties with natural gases produced from crude oils. Fuel gases produced from a mixture of polymer wastes mainly contain alkanes lighter than hexane, with methane and ethane being the predominant components. However, light non-hydrocarbons including nitrogen, carbon dioxide, and hydrogen sulphide are also common, their proportions being related to the reservoir where they originate from. The liquid fuel was produced in the temperature ranges from $70^{\circ} \mathrm{C}$ to $120^{\circ} \mathrm{C}$ and from $175^{\circ} \mathrm{C}$ to $300^{\circ} \mathrm{C}$ for naphtha $\left(\mathrm{C}_{7-}\right.$ $\left.\mathrm{C}_{10}\right)$ and kerosene $\left(\mathrm{C}_{12}-\mathrm{C}_{15}\right)$ respectively. Both components are liquids, have color (light yellow for naphtha), flammables and fuel odor is plastic and benzene smell.

Perkin Elmer FT-IR (Fourier Transform Infra-red Spectroscopy) was used to analyse the liquid products as presented in Figure 3 and 4. FT-IR analysis of liquid hydrocarbon components from waste polymer mixtures was in accordance with the wave number following types of functional groups appeared in the analysis. The raw materials which mainly include LDPE, PP and PS have aromatic compounds such as benzene, toluene, ethyl benzene, styrene, $\alpha$-methylstyrene, propyl-benzene, 2-propenyl-benzene, pentyl-benzene, heptyl-benzene and so on. Figure 3 shows the FT-IR spectrum of the thermally degraded product of waste plastics that corresponds to Naphtha. The wave number values of the most important peaks are summarized in Table 1. The broad band at $3649.20 \mathrm{~cm}^{-1}$ is due to free O$\mathrm{H}$ stretching which is derived functional group, peak at $3063.12 \mathrm{~cm}^{-1}$ corresponds to $(=\mathrm{C}-\mathrm{H})$ stretching, wave 
number $2933.39 \mathrm{~cm}^{-1}, 2730.96 \mathrm{~cm}^{-1}$ and $2669.39 \mathrm{~cm}^{-1}$ are due to $\mathrm{C}-\mathrm{CH}_{3}$ stretching, wave number $1912.17 \mathrm{~cm}^{-1}, 1871.71$ $\mathrm{cm}^{-1}, 1816.9 \mathrm{~cm}^{-1}, 1799.77 \mathrm{~cm}^{-1}$, and $1641.16 \mathrm{~cm}^{-1}$ for nonconjugated double bonds, wave number $1604.49 \mathrm{~cm}^{-1}$ for functional group with conjugated system. In addition to this the peaks appeared at $1495.49 \mathrm{~cm}^{-1}, 1460.04 \mathrm{~cm}^{-1}$ and $1377.42 \mathrm{~cm}^{-1}$ corresponds to $\mathrm{CH}_{2} \& \mathrm{CH}_{3}, 1030.23 \mathrm{~cm}^{-1}$ is due to acetates, wave number $990.81 \mathrm{~cm}^{-1}$ and $965.23 \mathrm{~cm}^{-1}$ for $\mathrm{CH}=\mathrm{CH}_{2}$ functional group and wave number $907.32 \mathrm{~cm}^{-1}$ for
$\mathrm{C}=\mathrm{CH}_{2}$ functional group and wave number $721.84 \mathrm{~cm}^{-1}$ is due to $-\mathrm{CH}=\mathrm{CH}$ (cis). In general from the FT-IR data indicates the presence of hydroxyl function group, Carbonhydrogen stretching, conjugated and non-conjugated system in the sample analysed. Generally, some groups are emerged single and double bonded functional groups. Methyl and methylene groups are also seen in the spectrum. The Table 1 below shows for medium and strong spectrums but not more for finger points.

Table 1. FT-IR spectrum wave number for the product that corresponds to Naphtha.

\begin{tabular}{|c|c|c|c|c|c|}
\hline $\begin{array}{l}\text { Band seria } \\
\text { Number }\end{array}$ & $\begin{array}{l}\text { Wave number } \\
\text { In } \mathrm{cm}^{-1}\end{array}$ & $\begin{array}{l}\text { Type of functional } \\
\text { group }\end{array}$ & $\begin{array}{l}\text { Band serial } \\
\text { Number }\end{array}$ & $\begin{array}{l}\text { Wave number } \\
\text { In } \mathrm{cm}^{-1}\end{array}$ & $\begin{array}{l}\text { Type of functional } \\
\text { group }\end{array}$ \\
\hline 1 & 3649.20 & Free O-H & 11 & 1495.49 & $\mathrm{CH}_{2}$ \\
\hline 2 & 3063.12 & $=\mathrm{C}-\mathrm{H}$ & 12 & 1377.42 & $\mathrm{CH}_{3}$ \\
\hline 3 & 2933.39 & $\mathrm{C}-\mathrm{CH}_{3}$ & 13 & 1030.23 & acetates \\
\hline 4 & 2730.96 & $\mathrm{C}-\mathrm{CH}_{3}$ & 14 & 1020.94 & acetates \\
\hline 5 & 2669.39 & $\mathrm{C}-\mathrm{CH}_{3}$ & 15 & 990.81 & $\mathrm{O}-\mathrm{H}$ binding \\
\hline 6 & 1871.71 & Non-conjugated & 16 & 965.23 & $-\mathrm{CH}=\mathrm{CH}(\operatorname{trans})$ \\
\hline 7 & 1816.96 & Non-conjugated & 17 & 906.50 & $-\mathrm{CH}=\mathrm{CH}$ \\
\hline 8 & 1799.77 & Non-conjugated & 18 & 700.77 & $-\mathrm{CH}=\mathrm{CH}$ (cis) \\
\hline 9 & 1636.49 & conjugated & & & \\
\hline 10 & 1604.21 & conjugated & & & \\
\hline
\end{tabular}

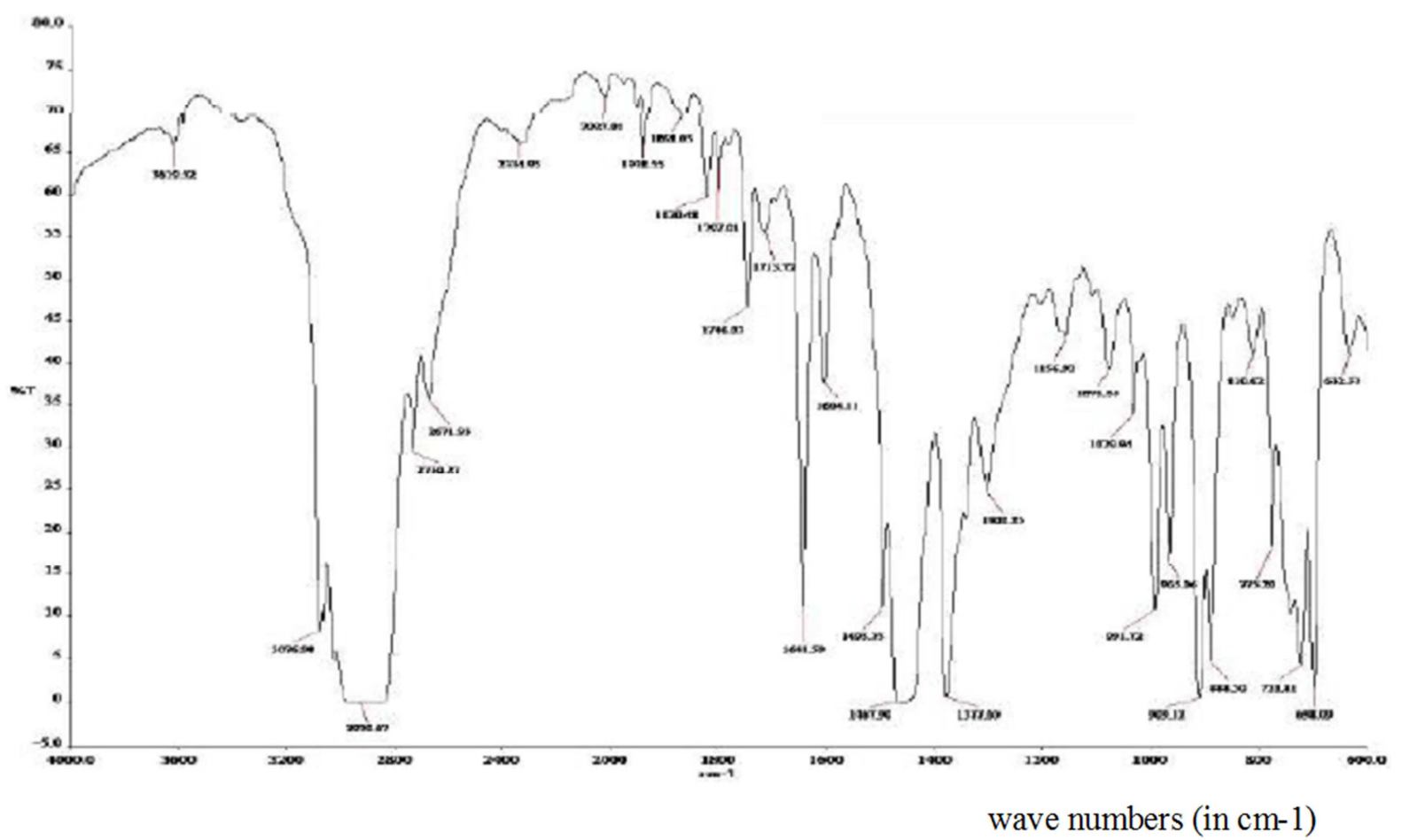

Figure 3. FT-IR spectrum for the thermally degraded waste plastics (the product corresponds to Naphtha).

Figure 4 shows the FT-IR spectrum of the thermally degraded product of waste plastics that corresponds to kerosene. The wave number values of the major peaks are summarized in Table 2. The absorptions in the $3619.52 \mathrm{~cm}^{-1}$ indicates $\mathrm{O}-\mathrm{H}$ stretching, wave number $3070.50 \mathrm{~cm}^{-1}$, hydrogen's are attached to both $\mathrm{sp}^{2}$ carbons $(=\mathrm{C}-\mathrm{H})$ and wave number such as $2979.07 \mathrm{~cm}^{-1}, 2730.77 \mathrm{~cm}^{-1}$, and $2671.66 \mathrm{~cm}^{-1}$ indicates the presence of $\mathrm{C}-\mathrm{CH}_{3}$ stretching. Wave number $1938.55 \mathrm{~cm}^{-1}, 1820.48 \mathrm{~cm}^{-1}$ and $1797.01 \mathrm{~cm}^{-1}, 1746.05 \mathrm{~cm}^{-1}$ and $1713.77 \mathrm{~cm}^{-1}$ functional group is Non-Conjugated, wave number $1641.49 \mathrm{~cm}^{-1}, 1601.11 \mathrm{~cm}^{-1}$ functional group is Conjugated etc. In the middle of the spectrum wave number $1467.92 \mathrm{~cm}^{-1}$ and $1377.65 \mathrm{~cm}^{-1}$ indicates functional group is $\mathrm{CH}_{2}$ and $\mathrm{CH}_{3}$, wave number $1020.94 \mathrm{~cm}^{-1}$ functional group is acetates etc. Eventually, at the end of the spectrum peaks wave number $991.70 \mathrm{~cm}^{-1}$ and $965.01 \mathrm{~cm}^{-1}$ functional group is terminal alkenes (or- $\mathrm{CH}=\mathrm{CH}_{2}$ ) with alkyl substituent and wave number $730.21 \mathrm{~cm}^{-1}$ functional group is $-\mathrm{CH}=\mathrm{CH}$ (cis). Table 2 below also shows for medium and strong spectrums but not more for fingerpoints. 
Table 2. FT-IR spectrum wave number for the product that corresponds to Kerosene.

\begin{tabular}{|c|c|c|c|c|c|}
\hline $\begin{array}{l}\text { Band serial } \\
\text { Number } \\
\end{array}$ & $\begin{array}{l}\text { Wave number } \\
\text { In } \mathbf{c m}^{-1}\end{array}$ & $\begin{array}{l}\text { Type of functional } \\
\text { group }\end{array}$ & $\begin{array}{l}\text { Band serial } \\
\text { Number } \\
\end{array}$ & $\begin{array}{l}\text { Wave number } \\
\text { In } \mathrm{cm}^{-1}\end{array}$ & $\begin{array}{l}\text { Type of functional } \\
\text { group }\end{array}$ \\
\hline 1 & 3619.52 & Free O-H & 12. & 1467.92 & $\mathrm{CH}_{2}$ \\
\hline 2 & 3070.50 & $=\mathrm{C}-\mathrm{H}$ & 13. & 1377.65 & $\mathrm{CH}_{3}$ \\
\hline 3 & 2979.07 & $\mathrm{C}-\mathrm{CH}_{3}$ & 14. & 1020.94 & acetates \\
\hline 4 & 2730.77 & $\mathrm{C}-\mathrm{CH}_{3}$ & 15. & 991.70 & $\mathrm{O}-\mathrm{H}$ binding \\
\hline 5 & 2671.93 & $\mathrm{C}-\mathrm{CH}_{3}$ & 16. & 965.01 & $-\mathrm{CH}=\mathrm{CH}$ (trans) \\
\hline 6 & 1938.55 & Non-conjugated & 17. & 909.12 & $-\mathrm{CH}=\mathrm{CH}$ \\
\hline 7 & 1820.48 & Non-conjugated & 18. & 730.21 & $-\mathrm{CH}=\mathrm{CH}$ (cis) \\
\hline 8 & 1797.01 & Non-conjugated & & & \\
\hline 9 & 1746.05 & Non-conjugated & & & \\
\hline 9 & 1713.77 & Non-conjugated & & & \\
\hline 10 & 1641.49 & Conjugated & & & \\
\hline 11 & 1601.11 & Conjugated & & & \\
\hline
\end{tabular}

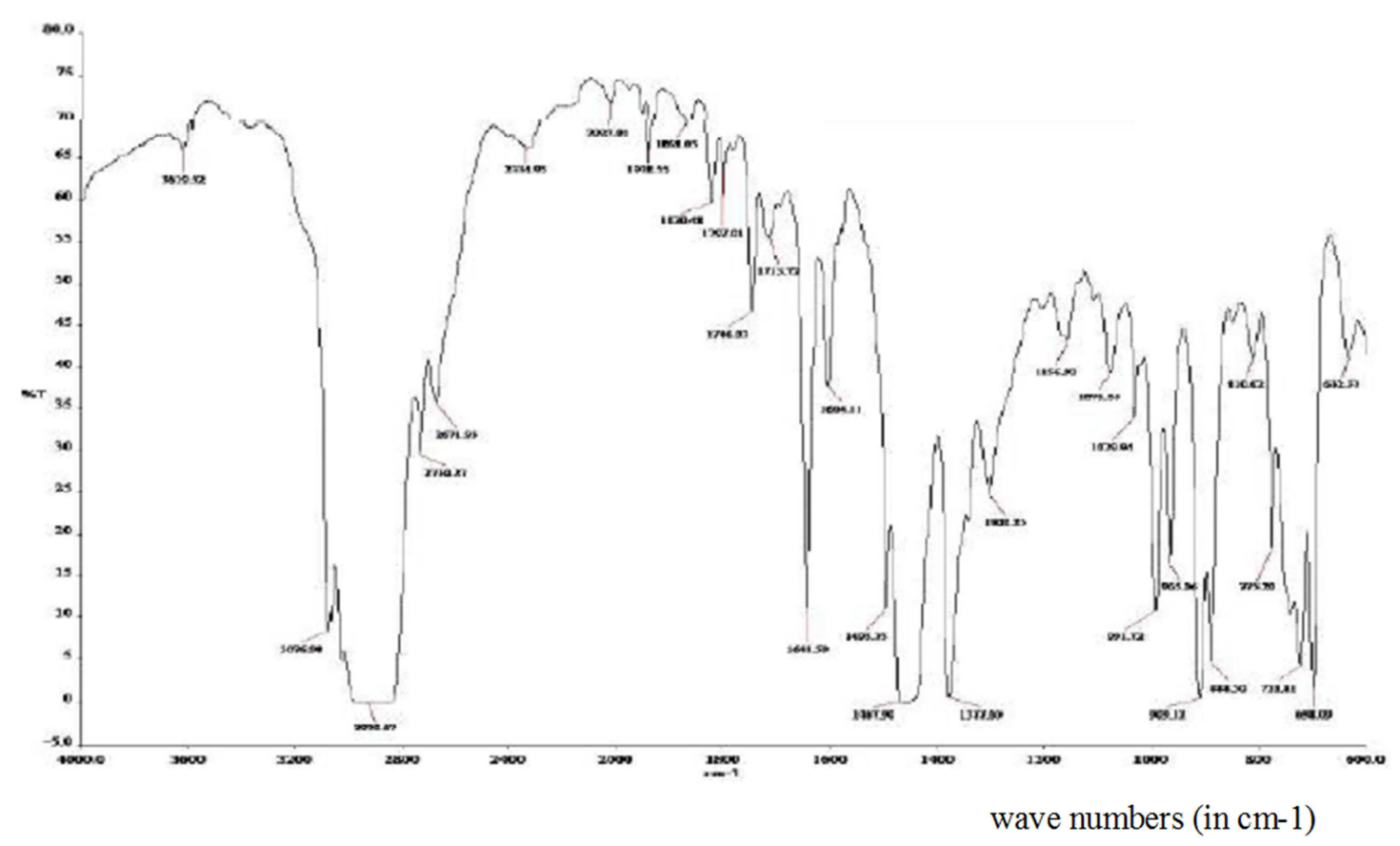

Figure 4. FT-IR spectrum for the thermally degraded waste plastics (the product corresponds to Kerosene).

\section{Conclusion}

Reactor chamber, which operates up to $300^{\circ} \mathrm{C}$ was designed and manufactured for the purpose producing hydrocarbon fuels from thermal degradation of waste plastics without using catalyst. We fed different collected waste plastics including LDPE, PP and PP gas into the reactor and as a result gas and liquid fuels were generated and came out of the reactor at different temperature ranges based of their boiling points. The lighter gases was generated in the temperature range from $40^{\circ} \mathrm{C}$ to $60^{\circ} \mathrm{C}$, whereas the liquid fuels were in the temperature ranges from $70^{\circ} \mathrm{C}$ to $120^{\circ} \mathrm{C}$ and from $175^{\circ} \mathrm{C}$ to $300^{\circ} \mathrm{C}$ which corresponds to naphtha (C7$\mathrm{C} 10)$ and kerosene (C12-C15) respectively. This technology would significantly reduce the environmental concern since the rapid rate of plastic consumption throughout the world has led to the creation of increasing amounts of waste and poses greater difficulties for disposal. It also generates fuel from waste.

\section{Acknowledgements}

The authors acknowledge Debre Berhan University for their financial support and Ethiopian Metals Industry Development Institute for manufacturing the designed solid decomposer chamber and Addis Ababa University for their help in FT-IR measurement.

\section{Conflict of Interest}

The authors declare that there is no conflict of interest.

\section{References}

[1] Mohammad M., (2011), waste plastic conversion into chemical product, journal of fundamentals of renewable energy and applications, (1): 1-6. 
[2] Browne, M. A., et al, (2011), Accumulations of micro-plastic on shorelines worldwide: Sources and sinks. Environ. Sci. Technol. 45, 9175-9179.

[3] Moinuddin S., et al, (2012), A new technology proposed to recycle waste plastics into hydrocarbon fuel in USA, international journal of energy and environment, 3(5), 749760 .

[4] Passamonti J. Sedran, U., (2012), Recycling of waste plastics into fuels. LDPE conversion in FCC, Appl Catal B Environ $125,499-506$.

[5] Donglei Wu, et al (2010), Low temperature conversion of plastic waste into light hydrocarbons, Elsevier 179, 15-20.

[6] Nitul L., (2015), recycling of plastic wastes, (2): 43-48.

[7] Hayelom Dargo (2014), Recycling of plastic waste into fuels, science publishing, international journal of Science, Technology and Society, 2(6): 190-195.

[8] Kumar S., (2011), Recovery of hydrocarbon liquid from waste high density polyethylene by thermal pyrolysis, Brazilian Journal of Chemical Engineering, 28(4), 659- 667.

[9] Miskolczi N. (2006), High energy containing fractions from plastic wastes by their chemical recycling, Macromol Symp, 4(7): 599-606.

[10] Mustapha Garba1, David Jackson, (2017), Catalytic upgrading of refinery cracked products by trans hydrogenation: a review, Appl Petrochem Res, 7: 1-8.

[11] Amrita k., (2015), recycling and pyrolysis of waste plastics, in. journal of research, 3(9):1-3.
[12] Anil V., et al, (2015), Pyrolysis of PE using the Various Catalysts, 4(8): 039-043.

[13] Asanuma M.,(2004), Recycling of waste plastics in blast furnace. Jpn Inst Energy, 83(4), 252-256.

[14] Balakrishnan C., (2007), Thermal degradation of polystyrene in the presence of hydrogen by catalysts in solution, Polymer Degradation and Stability, (92), 1583-1591.

[15] Delattre C, (2001), Improvement of the micro activity test for kinetic and deactivation studies involved in catalytic cracking, Chem Eng Sci, 56(4): 1337-1345.

[16] Gaurav M., (2014), Conversion of LDPE Plastic waste into liquid fuel by thermal degradation, 2(4): 104-107.

[17] Jagram M., et al, (2015), A Study on polymer \& plastic waste and recycling, international Journal of Recent Scientific research, 6(3): 2968-2971.

[18] Kumar S., (2011), Recovery of hydrocarbon liquid from waste high density polyethylene by thermal pyrolysis, Brazilian Journal of Chemical Engineering, 28 (4): 659-667.

[19] Miskolczi N. (2006), High energy containing fractions from plastic wastes by their chemical recycling, Macromol Symp, 4(7): 599-606.

[20] James O, etal, (2016), Lower alkanes dehydrogenation: strategies and reaction routes to corresponding alkenes, Fuel Process Technol 149:239-255.

[21] Jackson S., et al, (1997), Deactivation and regeneration of alkane dehydrogenation catalysts, Elsevier, Amsterdam, 7, $167-174$. 